\title{
Cateterismo posterior do plexo braquial em cão: estudo radiológico e avaliação de três protocolos anestésicos na duração do bloqueio motor e sensitivo
}

\author{
[Posterior catheterization of the brachial plexus: radiological study and evaluation of three \\ anesthetic protocols in motor and sensory block duration] \\ A.N. Teixeira ${ }^{1}$, P.O.B. Jesus ${ }^{1}$, F. Antunes ${ }^{1}$, B.A. Mota ${ }^{2}$ \\ ${ }^{1}$ Universidade Estadual do Norte Fluminense Darcy Ribeiro - Campos dos Goytacazes, RJ \\ ${ }^{2}$ Médica veterinária autônoma
}

\begin{abstract}
RESUMO
Avaliou-se a eficiência do cateterismo posterior do plexo braquial em cães para promover bloqueio motor e sensitivo, por meio de três protocolos anestésicos. Foram utilizados nove cães, machos e fêmeas, sem distinção de raça e idade, com peso variando de 6 a 15kg, distribuídos em três grupos de três animais por grupo. Após a confirmação do correto posicionamento do cateter pela via posterior do plexo braquial por meio do exame radiográfico, foram aplicadas as medicações de acordo com os grupos. No grupo 1, a solução anestésica de bupivacaína $0,5 \%$ sem vasoconstrictor, na dose de $2 \mathrm{mg}^{\mathrm{kg}} \mathrm{kg}^{-1}$, foi usada isoladamente. No grupo 2, a solução anestésica de bupivacaína foi associada ao butorfanol na dose de $0,25 \mathrm{mg} \cdot \mathrm{kg}^{-1}$. No grupo 3, o fentanil, na dose de $0,005 \mathrm{mg} \cdot \mathrm{kg}^{1}$, foi associado à solução anestésica de bupivacaína. Não houve diferença estatística significante entre os grupos. Observou-se que a duração dos bloqueios motor e sensitivo foi clinicamente maior no grupo 2. O cateterismo posterior do plexo braquial permite a aplicação de fármacos mais próximos do plexo nervoso, promovendo analgesia complementar nos membros anteriores.
\end{abstract}

Palavras-chave: cão, bloqueio posterior do plexo braquial, bupivacaína, butorfanol, fentanil

\begin{abstract}
We evaluated the efficiency of the posterior brachial plexus catheterization in dogs to promote motor and sensory block using three anesthetic protocols. We used nine dogs, males and females, without distinction of race and age, weighing 6 to $15 \mathrm{~kg}$ which were divided into three groups of three animals per group. After confirming the correct positioning of the catheter through the posterior brachial plexus through radiographic examination, the medications were administered according to the groups. In group 1 the anesthetic bupivacaine 0.5\% without a vasoconstrictor dose of $2 \mathrm{mg} . \mathrm{kg}-1$ was used alone. In group 2 the anesthetic bupivacaine was associated with butorphanol at a dose of 0.25mg.kg-1. In group 3, the fentanyl dose was associated with 0.005mg.kgl anesthetic bupivacaine. There was no statistically significant difference between groups. It was observed that the duration of sensory and motor block was clinically higher in group 2. The posterior brachial plexus catheterization allows the application of drugs closer to the nerve plexus promoting additional analgesia in the forelimbs.
\end{abstract}

Keywords: dog, posterior blockade of brachial plexus, bupivacaine, butorphanol, fentanyl

\section{INTRODUÇÃO}

O interesse por técnicas de anestesia regional tem sido crescente na prática anestésica em pequenos animais (Portela et al., 2010). A anestesia geral pode ser vantajosa quando se deseja completa imobilização e relaxamento muscular, entretanto a anestesia local, seja ela tópica, infiltrativa ou regional, é uma técnica que, associada a qualquer medicação préanestésica, promove anestesia cirúrgica quando o paciente é considerado de risco (Thurmon, 1996).

Recebido em 2 de dezembro de 2012

Aceito em 7 de fevereiro de 2013

E-mail: andersonteixeiravet@hotmail.com 
Atualmente a anestesia regional em pequenos animais tem sido utilizada em associação à anestesia geral, contribuindo, dessa maneira, para a diminuição da utilização de anestésicos gerais (Thiesen, 2007). Técnicas de anestesia regional têm sido utilizadas no controle da dor dos animais domésticos, porém há necessidade de protocolos que propiciem o alívio da dor de uma forma contínua.

Selander et al. (1977) foram os primeiros pesquisadores a utilizarem o método de analgesia continua, por meio do cateterismo axilar do plexo braquial em humanos. Nessa mesma época, houve a instituição do protocolo de cateterismo peridural para a analgesia contínua de membros inferiores.

A anestesia regional do plexo braquial é eficaz para o controle da dor dos pacientes cirúrgicos no período perioperatório e pós-operatório, porém a analgesia pós-operatória fica limitada ao uso de fármacos no momento da punção do plexo. Ao mesmo tempo, o plexo braquial é uma região ricamente vascularizada, o que dificulta a ação dos fármacos no sítio de ação, devido à rápida absorção. Outra dificuldade para a realização dessa técnica é a prática que o anestesista deve ter para a realização desse tipo de bloqueio. Futema et al. (2002) descreveram a técnica com a finalidade de propiciar dados técnicos que facilitem o emprego dessa anestesia, por meio da descrição anatômica do acesso e do emprego do estimulador de nervos periféricos para a localização do plexo. Carvalho et al. (2008) avaliaram a anestesia paravertebral cervical no bloqueio anestésico dos membros torácicos e concluíram que é benéfica, porém o período hábil de anestesia ficou limitado, sendo uma técnica que não propicia efeito analgésico duradouro para o período pós-operatório dos animais.

O presente trabalho teve como objetivo aperfeiçoar a técnica do cateterismo posterior do plexo braquial e torná-la de fácil execução para a prática anestésica veterinária. Também visou avaliar a eficiência da bupivacaína a $0,5 \%$ na realização do bloqueio posterior do plexo braquial, e estudar a analgesia do butorfanol e do fentanil no plexo braquial de cães, avaliando seus efeitos no prolongamento dos bloqueios sensitivo e motor.

\section{MATERIAL E MÉTODOS}

Neste experimento, foram utilizados nove cães, provenientes do Centro de Controle de Zoonose de Campos do Goytacazes. Foram utilizados animais hígidos, machos e fêmeas, sem distinção de raça e idade, com peso variando de 6 a $15 \mathrm{~kg}$. Todos os animais foram avaliados clinicamente por meio das frequências cardíaca e respiratória, aferição da temperatura retal, coloração de mucosas, tempo de preenchimento capilar (TPC), palpação de linfonodos e auscultação cardíaca e pulmonar. Também foram realizados exames laboratoriais, que consistiram de hemograma, ureia, creatinina, ALT e AST. As avaliações clínica e laboratorial dos animais tiveram como objetivo utilizar animais saudáveis para que não houvesse qualquer tipo de alteração na metabolização dos fármacos. $\mathrm{O}$ jejum alimentar $\mathrm{e}$ o hídrico estipulados foram de 12 e seis horas, respectivamente.

Cada animal foi canulado na veia cefálica com cateter específico e recebeu solução fisiológica na velocidade de infusão $10 \mathrm{~mL} / \mathrm{kg} / \mathrm{h}$. Foram realizadas a tricotomia e a antissepsia do membro a ser submetido ao bloqueio. Os animais foram sedados com acepromazina na dose de $0,05 \mathrm{mg} \cdot \mathrm{kg}^{-1}$ pela via intramuscular e, após 15 minutos, induzidos com propofol, dose-efeito pela via intravenosa.

Os animais foram posicionados em decúbito lateral, com o membro que seria submetido ao bloqueio voltado para a superfície da mesa. Primeiramente era localizada a borda dorsal da escápula, então se introduzia o cateter a partir da borda dorsal da escápula em direção ao colo da escápula, com bisel do cateter sempre em contato com o periósteo na superfície medial da escápula. Após a completa introdução do cateter, os animais foram submetidos a estudo radiográfico, para que fosse possível avaliar a posição do cateter em relação ao plexo braquial, e, em seguida, foi depositada a solução anestésica.

Os cães foram distribuídos aleatoriamente em três grupos de três animais cada. Em todos os animais foi realizado o cateterismo posterior do plexo braquial, variando somente o protocolo entre os grupos, como descrito: g 1 - os animais foram submetidos ao bloqueio posterior do plexo braquial utilizando-se a solução anestésica de 
bupivacaína $0,5 \%$ sem vasoconstrictor, na dose de $2 \mathrm{mg} . \mathrm{kg}^{-1}$; g 2 - os animais foram submetidos ao bloqueio posterior do plexo braquial utilizando-se a solução anestésica bupivacaína $0,5 \%$ sem vasoconstrictor, na dose de $2 \mathrm{mg} \cdot \mathrm{kg}^{-1}$, associada ao butorfanol na dose de $0,25 \mathrm{mg} \cdot \mathrm{kg}^{-1}$, segundo Troncy et al. (1996); g 3 - os animais foram submetidos ao bloqueio posterior do plexo braquial utilizando-se a solução anestésica bupivacaína $0,5 \%$ sem vasoconstrictor, na dose de $2 \mathrm{mg} \cdot \mathrm{kg}^{-1}$, associada ao fentanil na dose 0,005mg.kg ${ }^{1}$, segundo Otero (2005).

As características do bloqueio foram avaliadas por três avaliadores, previamente treinados para a realização dessa tarefa, em duplo-cego, ou seja, os avaliadores não souberam que fármaco foi utilizado no animal o qual avaliaram.

As variáveis avaliadas no bloqueio foram: tempo de realização da técnica: tempo desde a inserção da agulha até o término da técnica; tempo de latência sensitiva: tempo desde o término da técnica até a ausência da resposta dolorosa provocada pelo pinçamento da região interdigital e da pele, tanto na porção cranial do rádio quanto da pele nas porções cranial e lateral do úmero. A resposta dolorosa é comprovada pela atitude do animal ao pinçamento pelos critérios: meneios de cabeça, vocalização, tentativa de mordedura, movimentos de outras partes do corpo e reflexos de defesa, como flexão do membro fugaz; tempo de latência motora: período desde o término da técnica até a ausência da resposta motora do membro provocada pelo pinçamento da região interdigital e da pele, tanto na porção cranial do rádio quanto da pele nas porções cranial e lateral do úmero. A resposta motora será comprovada pela flexão do membro após o pinçamento; duração analgésica: período desde o início do bloqueio sensitivo até a volta da sensibilidade dolorosa do membro, a qual será comprovada pelo método do pinçamento descrito igualmente para avaliação do tempo de latência sensitiva.

Para a comparação dos grupos, foi feita análise estatística das médias com testes de NewmanKeuls e de Tukey com $95 \%$ de confiabilidade, utilizando-se o software GraphPad Prism 5.

\section{RESULTADOS E DISCUSSÃO}

Após a realização do projeto piloto, o anestesista responsável pela realização do bloqueio estava habilitado para fazê-lo em cinco minutos. Se a técnica do cateterismo posterior do plexo braquial demorasse mais do que o tempo predeterminado, o animal era excluído do experimento, mas isso não aconteceu durante o desenvolvimento do trabalho.

Uma dificuldade inicial na passagem do cateter foi atribuída à intensa musculatura do local envolvido, impossibilitando o posicionamento do cateter no local pretendido. Após muitas tentativas, notou-se que a mudança de decúbito do animal, posicionando o membro a ser anestesiado em contato com a mesa, facilitou a passagem do cateter até a proximidade da articulação escapuloumeral (Fig. 1).

Posteriormente à cateterização, os animais foram radiografados com a finalidade de se determinar o posicionamento do cateter em relação ao plexo braquial (Fig. 2), notando-se que a posição do cateter correspondia ao local exato pretendido para a deposição dos fármacos anestésicos.

Após os animais serem radiografados, era, então, depositada a solução anestésica de acordo com o grupo ao qual pertencia o animal. Um minuto após a administração da solução anestésica, a região interdigital e a pele, tanto na porção cranial ao rádio quanto nas porções cranial e lateral do úmero, foram pinçadas com uma pinça hemostática, com o objetivo de se mensurar a latência do bloqueio sensitivo e do bloqueio motor. O tempo encontrado para a latência tanto do bloqueio sensitivo quanto do bloqueio motor foi de exatamente um minuto para os três grupos. Não foi possível diferenciar a latência entre os bloqueios, uma vez que o tempo foi o mesmo.

A cada 10 minutos, começando a contar da perda da sensibilidade e da capacidade motora do membro, os animais tiveram a região interdigital e a pele, tanto na porção cranial ao rádio quanto nas porções cranial e lateral do úmero, pinçadas com uma pinça hemostática, com o objetivo de se determinar algum grau de recuperação da capacidade sensitiva e ou motora. A duração dos bloqueios sensitivo e motor mostrou-se clinicamente superior no grupo 2 , seguido pelo grupo 3. O grupo 1, em que a bupivacaína foi usada isoladamente, foi o grupo com menor tempo de bloqueio sensitivo e de bloqueio motor. Apesar de a diferença entre os grupos ter se mostrado evidente clinicamente, não houve 
diferença significativa entre os protocolos utilizados $(\mathrm{P}<0,05)$ (Fig. 3 e 4).

A proximidade do local de deposição da solução anestésica e o plexo braquial foram verificados por meio do estudo radiográfico, que demonstrou o cateter utilizado para a realização da técnica de bloqueio do plexo braquial chegando até o colo da escápula, local onde passam quase todas as ramificações nervosas provenientes do plexo braquial (Fig. 2). Segundo Fantoni e Cortopassi (2002), a eficiência da técnica de bloqueio regional está proporcionalmente ligada à capacidade de se depositar a solução anestésica o mais próximo possível do nervo ou do plexo que se deseja bloquear.

Foi possível observar a perda de propriocepção em um animal, que se recuperou da sedação e se posicionou em estação sobre a mesa. Também foi possível observar que o animal não apoiava corretamente o membro que foi anestesiado, e que voltou a apoiá-lo corretamente após o término de ação dos agentes anestésicos utilizados (Fig. 5). A falta de propriocepção neste animal após o bloqueio do plexo braquial demonstra a maior suscetibilidade das fibras de menor calibre à ação dos anestésicos locais, assim como foi citado por Goulart et al. (2005).

A bupivacaína tem um período de latência de 20 minutos e isso está diretamente ligado ao valor do seu pKa, que é de 8,1 (Otero, 2005). O período de latência sensitiva e motora encontrado no grupo 1, grupo em que a bupivacaína foi usada isoladamente, foi de um minuto, resultado que difere do que foi citado por Otero (2005).

O grupo 2 apresentou um período de latência sensitiva e motora igual a um minuto. Esse achado está de acordo com Albuquerque (2013), ao citar que a associação da bupivacaína ao butorfanol para a realização de anestesia epidural em mulheres grávidas diminuiu a latência do bloqueio.

O grupo 3 também apresentou período de latência sensitiva e motora de um minuto. Esse achado difere do de Nishikawa et al. (2000), que obtiveram um resultado inverso. Ao associar o fentanil à lidocaína para realizar o bloqueio de plexo braquial em 22 pessoas adultas submetidas à cirurgia eletiva na mão e no antebraço, estes autores observaram um aumento no período de latência do bloqueio.

A bupivacaína é capaz de promover um bloqueio sensitivo de 10 horas e um bloqueio motor de até seis horas, quando utilizada na concentração de 0,5\% (Otero, 2005). No grupo 1, a duração dos bloqueios sensitivo e motor foi de 66 (60-70) minutos para ambos os bloqueios, não havendo diferença de tempo entre a duração desses bloqueios. Essa diminuição no tempo de ação da bupivacaína pode ser explicada pela intensa vascularização presente no plexo braquial, o que aumenta a absorção sistêmica do anestésico e diminui a sua ação no local da administração. Segundo Futema et al. (2002), a associação de um vasoconstritor à bupivacaína tem o objetivo de diminuir a absorção desta, o que seria relevante nesse caso, prolongando o efeito da bupivacaína sobre o plexo braquial.

O grupo 2 apresentou bloqueios sensitivo e motor de 83 (80-90) minutos e 76 (60-80) minutos, respectivamente, e o grupo 3 apresentou bloqueio sensitivo de 73 (50-80) minutos e bloqueio motor de 76 (60-80) minutos. É possível observar que a associação de opioides à bupivacaína foi capaz de prolongar a duração tanto do bloqueio sensitivo quanto do bloqueio motor, semelhantemente ao resultado de Bazin (1997), que associou o sulfentanil à bupivacaína $0,5 \%$ e à lidocaína $1 \%$ na realização do bloqueio do plexo braquial em 40 pacientes submetidos à oteossíntese de antebraço e teve como resultado aumento na duração da analgesia pós-operatória. Bouaziz (2000) não evidenciou nenhuma melhoria no bloqueio sensitivo e/ou no motor após associar sulfentanil à mepivacaína 1,5\% para a realização de bloqueio do plexo braquial em 92 pessoas.

Apesar de não haver diferença significativa entre os grupos, é possível observar diferença clínica por meio do tempo de duração dos bloqueios, sendo o grupo 2 o que apresentou melhores resultados, seguido do grupo 3. Acredita-se que a não diferença significativa entre os grupos seja reflexo de uma pequena quantidade de animais utilizada neste trabalho. 


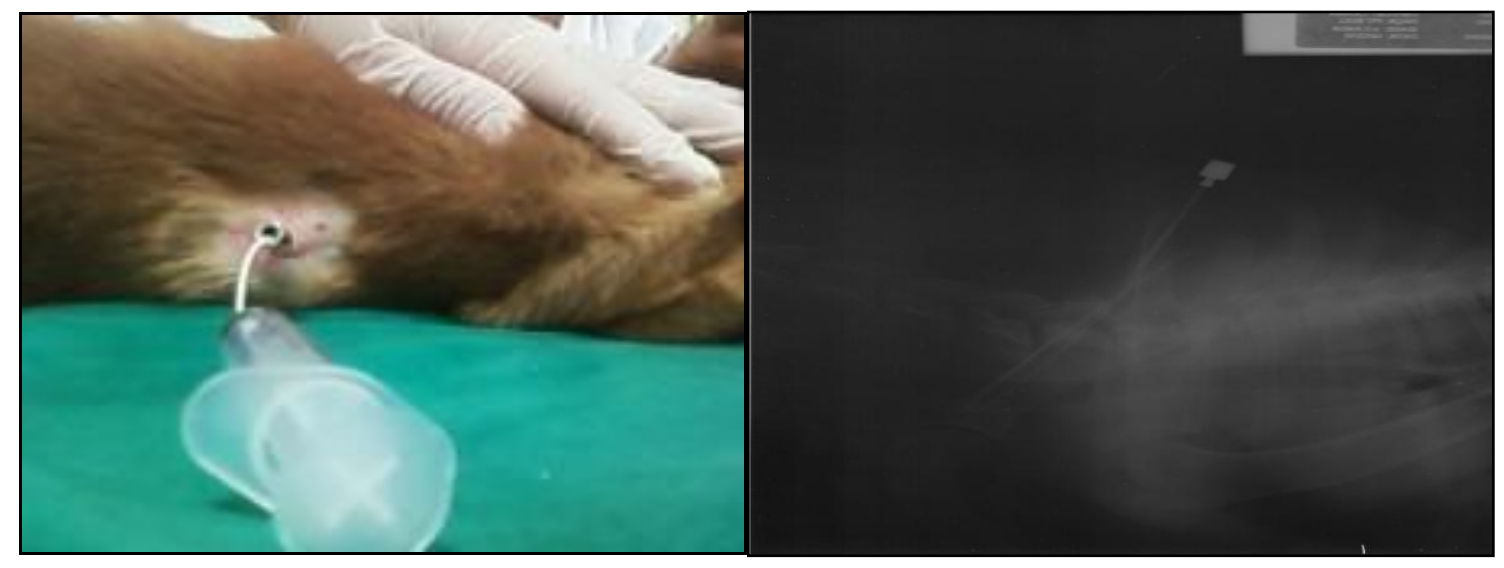

Figura 1. Imagem de um cão posicionado em decúbito lateral direito com o cateter posicionado para a realização da técnica do cateterismo posterior do plexo braquial (Fonte: Arquivo pessoal).

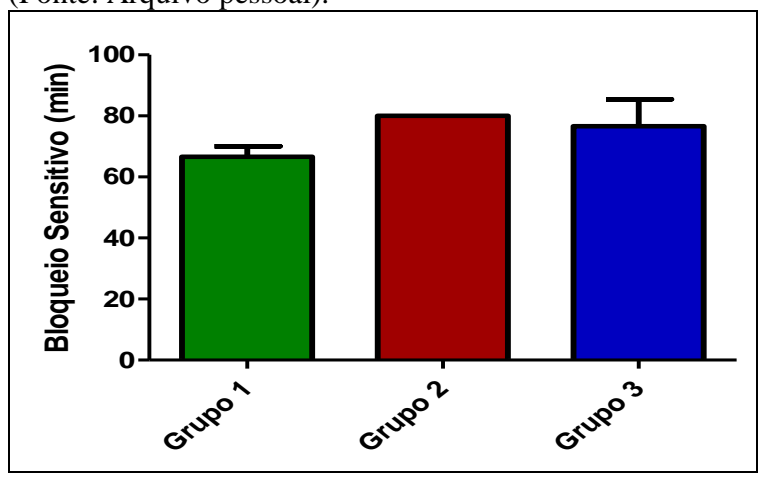

Figura 3. Duração do bloqueio sensitivo (minutos) após anestesia local do plexo braquial em cães ( $p>0,05)$. Grupo 1: bupivacaína $0,5 \%$ sem vasconstritor; grupo 2 : bupivacaína $0,5 \%$ sem vasconstritor + butorfanol; grupo 3 : bupivacaína $0,5 \%$ sem vasconstritor + fentanil.
Figura 2. Imagem radiográfica, com vista lateral, do posicionamento do cateter em um cão, demonstrando a espinha da escápula e o cateter chegando até o colo da escápula (Fonte: Arquivo pessoal).

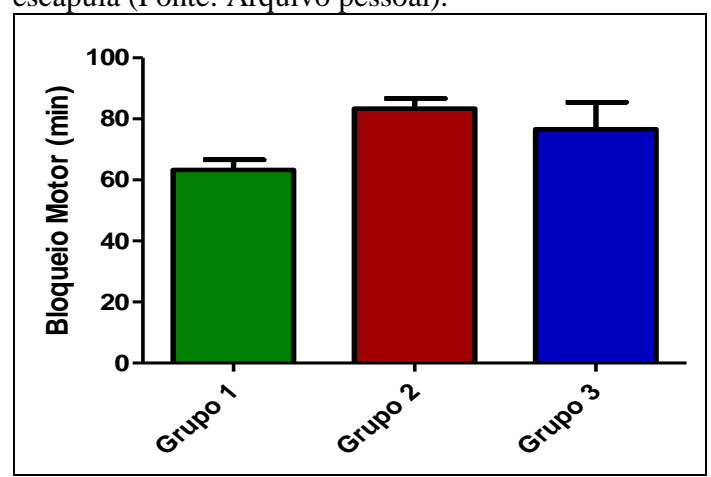

Figura 4. Duração do bloqueio motor (minutos) após anestesia local do plexo braquial em cães ( $p>0,05$ ). Grupo 1: bupivacaína $0,5 \%$ sem vasconstritor; grupo 2: bupivacaína $0,5 \%$ sem vasconstritor + butorfanol; grupo 3: bupivacaína $0,5 \%$ sem vasconstritor + fentanil.

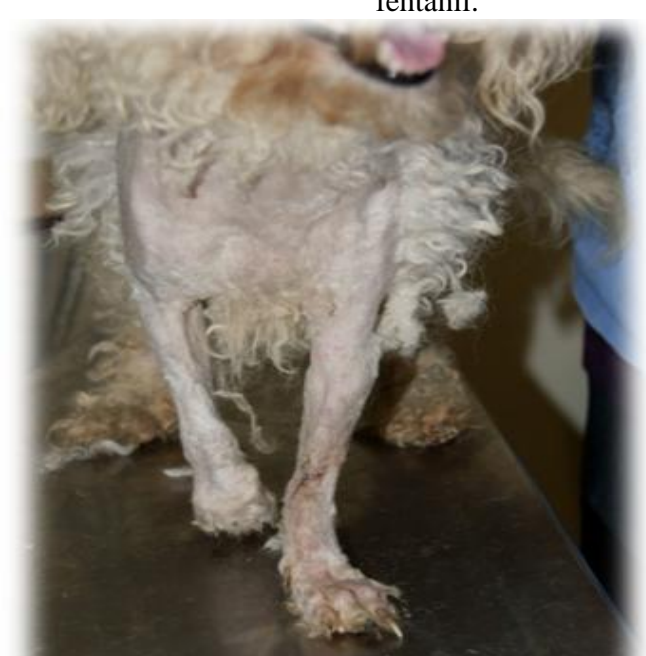

Figura 5. Imagem demonstrando a perda de propriocepção em um cão após a realização do bloqueio do plexo braquial (Fonte: Arquivo pessoal). 
Com o presente trabalho, pôde-se verificar que o cateterismo posterior do plexo braquial se mostrou tecnicamente fácil e clinicamente eficiente, sendo capaz de produzir analgesia complementar no membro torácico. A associação do butorfanol ou fentanil à bupivacaína $0,5 \%$ sem vasoconstritor promove analgesia adicional ou complementar em procedimentos nos membros torácicos. Novos estudos devem ser considerados com o objetivo de criar novos protocolos que aumentem o tempo de duração dos bloqueios motor e sensitivo.

\section{REFERÊNCIAS}

ALBUQUERQUE, V.B; SOUZA, T.F.B.; VIVAN, M.C.R. et al. Ropivacaína isolada ou associada a morfina, butorfanol ou tramadol pela via epidural em cadelas para realização de ovariosalpingohisterectomia. Vet. Zootec., v.20, p.111-123, 2013.

BAZIN, J.E.; MASSONI, C.; BRUELLE, P. et al. The addition of opioids to local anesthetics in brachial plexus block: the comparative effects of morphine, buprenorphine and sulfentanil. Anesthesia, v.52, p.858-862, 1997.

BOUAZIZ, H.; KINIRON, B.P.; MACALOU, D. et al. Sufentanil Does Not Prolong the Duration of Analgesia in a Mepivacaine Brachial Plexus Block: A Dose Response Study. Anesth. Analg., v.90, p.383, 2000.

CARVALHO, Y.K. Avaliação da anestesia paravertebral cervical no bloqueio anestésico local do membro torácico em cães. 2008.

FANTONI, D.T.; CORTOPASSI, S.R.G. Anestesia em cães e gatos. São Paulo: Roca, 2002. 389p.
FUTEMA F.; FANTONI D.T.; COSTA, J.O. et al. A new brachial plexus block technique in dogs. Vet. Anaesthesia and Analgesia. v.29, p.133-139, 2002.

GOULART, T.F.; HAMAJI, A.; KURIKI, W. Anestésicos Locais, Prát. Hosp., v.7, p.67-73, 2005 .

NISHIKAWA, K.; KANAYA, N.; NAKAYAMA, M. et al. Fentanyl Improves Analgesia but Prolongs the Onset of Axillary Brachial Plexus Block by Peripheral Mechanism. Anesth. Analg., v.91, p.384-387, 2000.

OTERO, P. Drogas Analgésicas. In: OTERO, P.E. Dor Avaliação e Tratamento em Pequenos Animais. São Paulo: Interbook Com. Imp. Livros Ltda, 2005. p.96-108.

PORTELA, D.A.; OTERO, P.E.; TARRAGONA, L. et al. Combined paravertebral plexus block and parasacral sciatic block in healthy dogs. Vet. Anaesthesia and Analgesia, v.37, p.531-541, 2010.

SELANDER, D. Catheter Technique in Axillary Plexus Block. Acta Anaesth. Scand., v.21, p.324329, 1977.

THIESEN, R. Bloqueio paravertebral do plexo braquial para amputação de membro torácico em cão - Relato de caso. Rev. Cienc. Vet. (Leme), v.5, p.27-30, 2007.

THURMON, J.C.; TRANQUILLI, W.J.; BENSON, G.J. Lumb \& Jones Veterinary Anesthesia. 3.ed. Philadelphia: Lippincott Villams \& Wilkins, 897p., 1996.

TRONCY, E; CUVELLIEZ, S.G; BLAIS, D. Evaluation of analgesia and cardiorespiratory effects of epidurally administered butorphanol in isoflurane anesthised dog. Am. J. Vet. Res., v.57, p.1478-1482, 1996. 